\title{
Internal Heat Generation/Absorption Effects on Unsteady Magneto Hydrodynamic Flow Over a Stretching Surface
}

\author{
Ajaykumar M. \\ Department of Mathematics \\ MIT Mysore, Belwadi -571477 \\ Karnataka, India
}

\author{
A.H. Srinivasa \\ Department of Mathematics \\ MIT Mysore, Belwadi -571477 \\ Karnataka, India
}

\begin{abstract}
The physical parameter outcomes of internal heat generation and absorption on magnetohydrodynamic fluid flow over a stretched surface with a Prandtl number are depicted graphically in this paper. The non-linear partial differential equation changed into ordinary differential equations and these equations were answered by numerically using the quasilinearization process along with an implicit finite difference scheme for leading the flow of heat transfer. The transfer of heat ratio at the surface level upsurges with rising data of heat generation $(\mathrm{Q}>0) /$ absorption $(\mathrm{Q}<0)$. The temperature increases as heat generation/absorption changes, as do the Prandtl number and magnetic parameters.
\end{abstract}

\section{Keywords}

MHD, unsteady flow, stretching surface, heat transfer, heat generation/absorption

\section{INTRODUCTION}

The flow over a stretching surface is significant in uses stated as hot rolling, metal revolving, wire drawing, extrusion, etc [1-3]. It is vital to identify the heat and fluid flow appearances of the procedure so that the final artefacts come across the preferred eminence specifications. The inventive work of Sakiadis [4] is studied over boundary layer behaviour on an incessant flat surface. Resulting from this, an abundant promise of work has been done over the last two years by L. J. Crane [5] and S. Sharidan [6] agreed upon by using several numerical techniques for different kinds of fluid flow with heat transfer conditions

Ishak [7] investigated MHD behaviour in boundary layer fluid flow and heat transfer due to a stretching surface. For heat transmission over an induced magnetic field, see Fadzilah et al. [8]. In the case of heat generation, Samad M A et al. [9] looked at steady magneto hydrodynamics heat and mass transfer natural convection fluid flow along a vertical extending surface. Anderson et al. [10] investigate the unstable transfer of heat delinquent over a stretching surface, which is stretched at a velocity that is time-dependent, and a new similarity result is formulated for the temperature field, which translates the time-dependent thermal energy equation to an ODE. The authors, Elbashbeshy and Bazid [11], considered the transfer of heat over an unsteady, stretching surface. In the current paper, we present the results of internal heat generation and absorption on unsteady magnetohydrodynamic boundary layer flow and the transfer of heat over a stretching surface.

\section{MATHEMATICAL FORMULISM}

Let us take into consideration a two-dimensional boundary layer fluid flow and the transferring of heat over a continuous stretching surface embedded in a moving incompressible, viscous fluid in the region $y>0$, as existing in Figure 1 . While observing the origin constant, two like and opposite forces can be applied quickly beside the $\mathrm{x}$-axis, which can result in stretching of the surface, causing a flow to be produced. At the same time, the wall temperature $\mathrm{Tw}(\mathrm{t}, \mathrm{x})$ of the surface is swiftly raised from $\operatorname{T} \infty$ to $\operatorname{Tw}(t, x)(>\operatorname{T} \infty)$. At the moment, the fluid flow is below the influence of the magneto hydrodynamics field Bo, which acts in a y-direction.

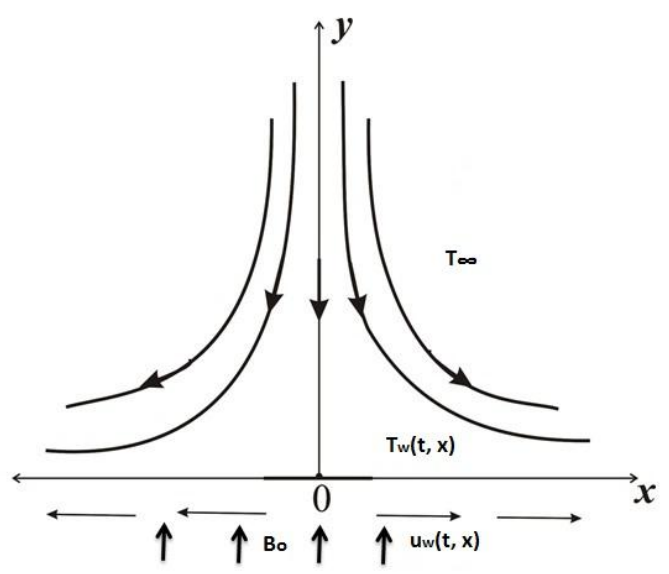

Figure 1: The Geometry and coordinate system.

The partial differential equations prominent to transferring of heat energy and momentum are specified by the unsteady boundary layer.

$\frac{\partial u}{\partial x}+\frac{\partial v}{\partial y}=0$

$\frac{\partial u}{\partial t}+u \frac{\partial u}{\partial x}+v \frac{\partial u}{\partial y}=\frac{1}{\rho} \frac{\partial^{2} u}{\partial y^{2}}-\frac{\sigma B_{0}^{2} u}{\rho}$

$\frac{\partial T}{\partial t}+u \frac{\partial T}{\partial x}+v \frac{\partial T}{\partial y}=\alpha \frac{\partial^{2} T}{\partial y^{2}}+\frac{Q_{o}}{\rho C_{p}}\left(T-T_{\infty}\right)$

Focus on the initial conditions here.

$t<0 ; u=v=0, T=T_{\infty}$ for any $x, y$

$t \geq 0 ; u=u_{w}(t, x), \quad v=0$

$T=T_{w}(t, x) u \rightarrow 0, T \rightarrow \infty$ aty $\rightarrow \infty$

Where $u$ and $\mathrm{v}$ symbolizes the velocity elements for $\mathrm{x}$ and $\mathrm{y}$ ways correspondingly, $t$ is the time, $\sigma$ denote the electrical conductivity, T denote the temperature, $\rho$-density and $\vartheta$ be the kinematic viscosity. $\alpha$ - thermal diffusivity, while $Q_{\mathrm{o}}$ is the element of heat generation/absorption.Here, let us take the 
surface velocity of $u_{w}(t, x)$ and the surface temperature $T_{w}(t, x)$ of the subsequent forms

$$
u_{w}(t, x)=\frac{c x}{1-\gamma t}, \quad T_{w}(t, x)=T_{\infty}+\frac{c}{2 \vartheta x^{2}(1-\gamma t)^{3 / 2}}
$$

Together $\mathrm{c}$ and $\gamma$ are in use as the positive constant here; let us add the new variables that follow,

$$
\begin{aligned}
\eta & =\sqrt{\frac{c}{\vartheta(1-\gamma t)}} y, \quad \psi=\sqrt{\frac{c \vartheta}{(1-\gamma t)}} x f(\eta) \\
T & =T_{\infty}+\frac{c}{2 \vartheta x^{2}(1-\gamma t)^{3 / 2}} \theta(\eta), \\
G & =\frac{T-T_{\infty}}{T_{W}-T_{\infty}}, \quad Q=\frac{Q_{o}(1-\gamma t)}{\rho C_{p}}
\end{aligned}
$$

Here $\psi$ is the function of the stream that is denoted as $u=\frac{\partial \psi}{\partial y}$ and $v=-\frac{\partial \psi}{\partial x}$,

We get the subsequent equations by substituting the transformations given in (5) and (6) into equations (1) to (3)

$$
\begin{aligned}
& f^{\prime \prime \prime}-M f^{\prime}-A\left(f^{\prime}+\frac{1}{2} \eta f^{\prime \prime}\right)-f^{\prime 2}+f f^{\prime \prime}=0 \\
& \frac{1}{P r} G^{\prime \prime}+Q G+f G^{\prime}+2 f^{\prime} G-\frac{1}{2} A\left(3 G+\eta G^{\prime}\right)=0
\end{aligned}
$$

Focus on the boundary conditions here (4), which are,

$f(0)=0, \quad f^{\prime}(0)=1, f^{\prime}(\infty)=0$

$G(0)=1$ or $G(\infty)=0$

Here, $\eta$ be the altered dimensionless vector, $f$ is use as the function of the dimensionless stream and the dimensionless velocity denoted by $f^{\prime}$. Where Pr be the Prandtl number, $G$ is dimensional temperature, $\mathrm{M}$ be the MHD parameter, $\mathrm{Q}$ be the heat generation and absorption parameter, $A$ be the nondimensional constant.

Here the skin friction factor $\left(c_{f}\right)$ and the transfer of heat factor in connections of Nusselt number $\left(N_{u}\right)$ are the parameters of significant interest in engineering.

$c_{f} \sqrt{\left(R_{e x}\right)}=\frac{\tau_{w}}{\rho\left(u_{w}\right)^{2}}=\frac{\mu\left(\frac{\partial u}{\partial y}\right)_{y=0}}{\rho\left(u_{w}\right)^{2}}=f^{\prime \prime}(0)$

Where dynamic viscosity denoted by $\mu, \tau_{\mathrm{w}}$ be taken the skin friction and $q_{w}$ denote the transfer of heat from the surface.

$\frac{N_{u}}{\sqrt{R_{e x}}}=\frac{x q_{w}}{k\left(T_{w}-T_{\infty}\right)}=\frac{-x k\left(\frac{\partial u}{\partial y}\right)_{y=0}}{k\left(T_{w}-T_{\infty}\right)}=-G^{\prime}$

Here $R_{e x}=\frac{u_{w} x}{\vartheta}$ is the Reynolds number.

\section{OUTCOMES AND CONFAB}

The non-linear order the numerical solutions to partial differential equations like (7) and (8) near the boundary conditions (9) were obtained by an implicit finite difference system along with a quasilinearization system. Inoue and Tate [12] and A. H. Srinivasa et al. [13] outline the procedure in detail after that. Here, consequent study outcomes display outstanding covenant when equated with the author Sharidan et al. [6] in the nonappearance of $\mathrm{Q}=0, \mathrm{M}=0$, for altered data of $(\operatorname{Pr})$ Prandtl number $=0.01,0.1,1.0$ using timedependent parameter (A) in Table. The results added are obtainable vividly from Figs. 2 to 5 .

\begin{tabular}{|c|c|c|c|c|c|c|c|c|c|c|c|c|}
\hline \multicolumn{13}{|c|}{$Q=0, M=0$} \\
\hline \multirow[t]{2}{*}{ A } & \multicolumn{4}{|c|}{0.8} & \multicolumn{4}{|c|}{1.2} & \multicolumn{4}{|c|}{2} \\
\hline & Present & Previous & Present & Previous & Present & Previous & Present & Previous & Present & Previous & Present & Previous \\
\hline Pr & $G^{\prime}(0)$ & $G^{\prime}(0)$ & $-f^{\prime \prime}(0)$ & $-f^{\prime \prime}(0)$ & $G^{\prime}(0)$ & $G^{\prime}(0)$ & $-f^{\prime \prime}(0)$ & $-f^{\prime \prime}(0)$ & $G^{\prime}(0)$ & $G^{\prime}(0)$ & $-f^{\prime \prime}(0)$ & $-f^{\prime \prime}(0)$ \\
\hline 0.01 & 0.2091 & 0.2092 & 1.2591 & 1.2610 & 0.2175 & 0.2174 & 1.3747 & 1.3777 & 0.2338 & 0.2331 & 1.5816 & 1.5873 \\
\hline 0.1 & 0.2630 & 0.2629 & 1.2591 & 1.2610 & 0.3305 & 0.3306 & 1.3747 & 1.3777 & 0.4457 & 0.4387 & 1.5816 & 1.5873 \\
\hline 1 & 0.4722 & 0.4712 & 1.2591 & 1.2610 & 0.7890 & 0.7882 & 1.3747 & 1.3777 & 1.2445 & 1.2437 & 1.5816 & 1.5873 \\
\hline
\end{tabular}
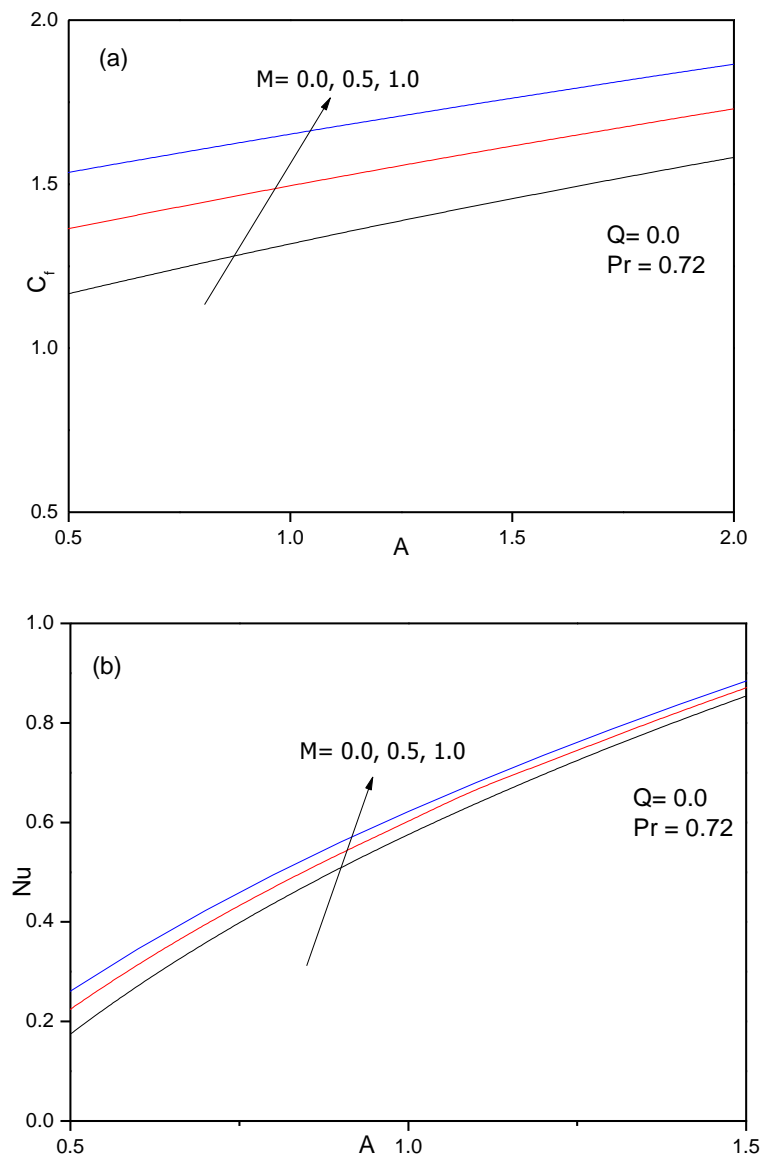

Figure 2(a) appearances Skin friction $\left[c_{f}\right]$ and $(b)$ transfer of heat $\left[N_{u}\right]$ for altered data of $M$

Table. Assessment results [6] for the transfer of heat $\left[G^{\prime}(0)\right]$, skin friction aspect $\left[f^{\prime \prime}(0)\right]$ for some data of $\operatorname{Pr}$ and A.

The overhead figure 2(a) \& 2(b) indicates the skin friction aspect $\left[c_{f}\right]$ and the transfer of heat $\left[N_{u}\right]$ factors and consequently together describes the raising values of magnetic field $\mathrm{M}$ for constant data of $\operatorname{Pr}=0.72$ and $Q=0.0$. Hence it is supposed that as magnetic parameter upsurges the ratio of rise in skin friction $\left[c_{f}\right]$ factor by $28.42 \%$ and transfer of heat $\left[N_{u}\right]$ factor by $2.12 \%$ in the sort of $0 \leq M \leq 1.0$. 

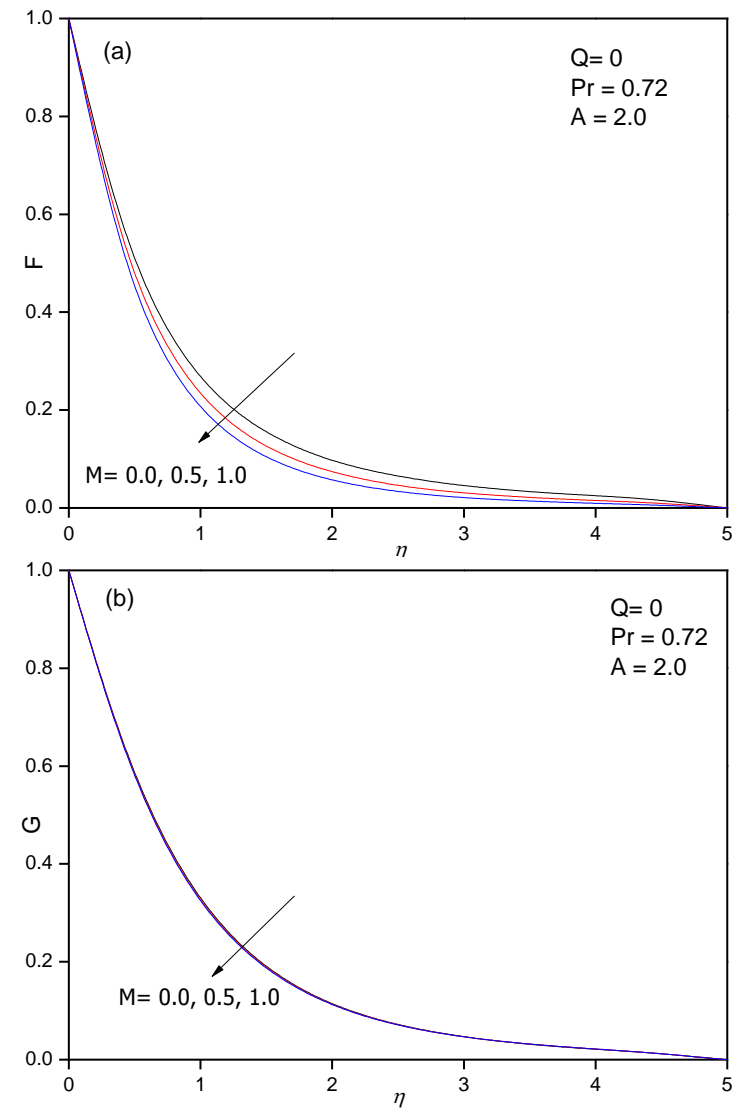

Figure 3(a) appearances velocity and (b) temperature aspect for reformed values of $M$

Figures 3(a) and 3(b) show the typical velocity and temperature aspects of different values of M.It is evidently supposed that, respectively, velocity and temperature decrease with the rising data of the magnetic field (M) parameter with $\mathrm{Q}=0.0, \operatorname{Pr}=0.72$, and $\mathrm{A}=2.0$. Hence, the electrically conducting fluid disturbs the fluid flow and decreases the thermal and momentum boundary layer thickness.

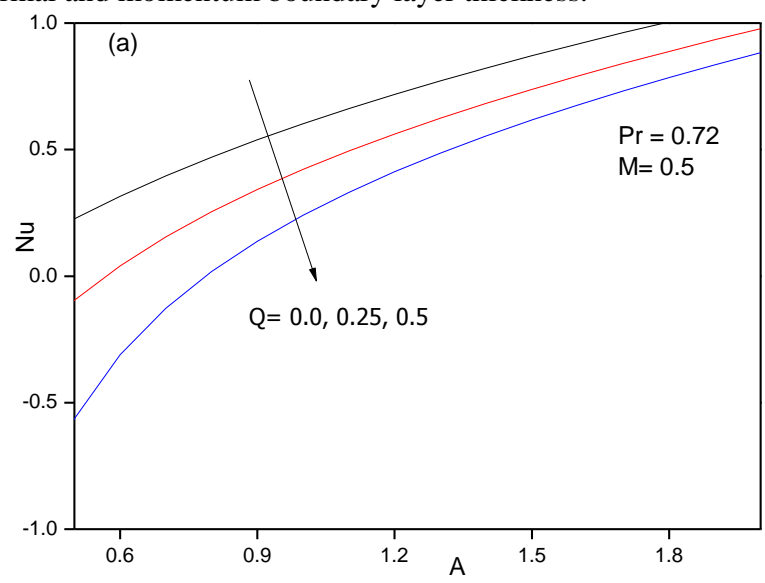

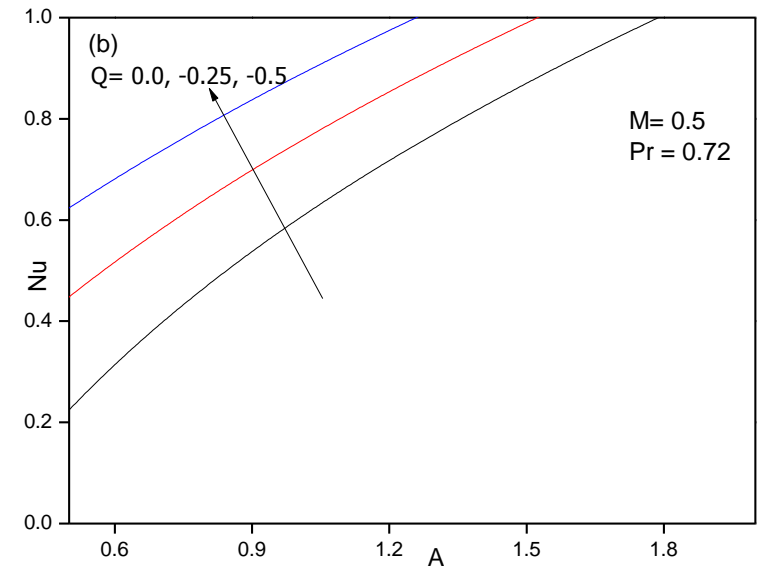

Figure 4. Illustrates influence of (a) heat generation aspect and (b) heat absorption $(Q)$ on heat transfer factor.

The impact of heat generation $(Q>0)$ /absorption parameter $(Q<0)$ on transferring of heat factor $N_{u}$ in the existence of the Prandtl number $(\mathrm{Pr}=0.72)$ and magnetic parameter $(M=0.5)$ is shown in Figure.4. It is perceived that $N_{u}$ declines with the rise of $Q(0 \leq Q \leq 0.5)$ for irrespective of heat generation. Indeed, the percentage of decline of $N_{u}$ when $Q$ rises from $Q=0.0$ to $Q=0.5$ at $A=1.5$ is $25.31 \%$ although the ratio of rise of $N_{u}$ when $Q$ declines from $Q=0.0$ to $Q=-0.5$ at $A=1.5$ is $22.77 \%$. This is recognized in depth that heat mechanism generation allows a layer of hot fluid flow nearby the surface and as a final stage, the fluid flow temperature outdoes the surface temperature, subsequent in a decline in the rate of heat transfer from the surface.
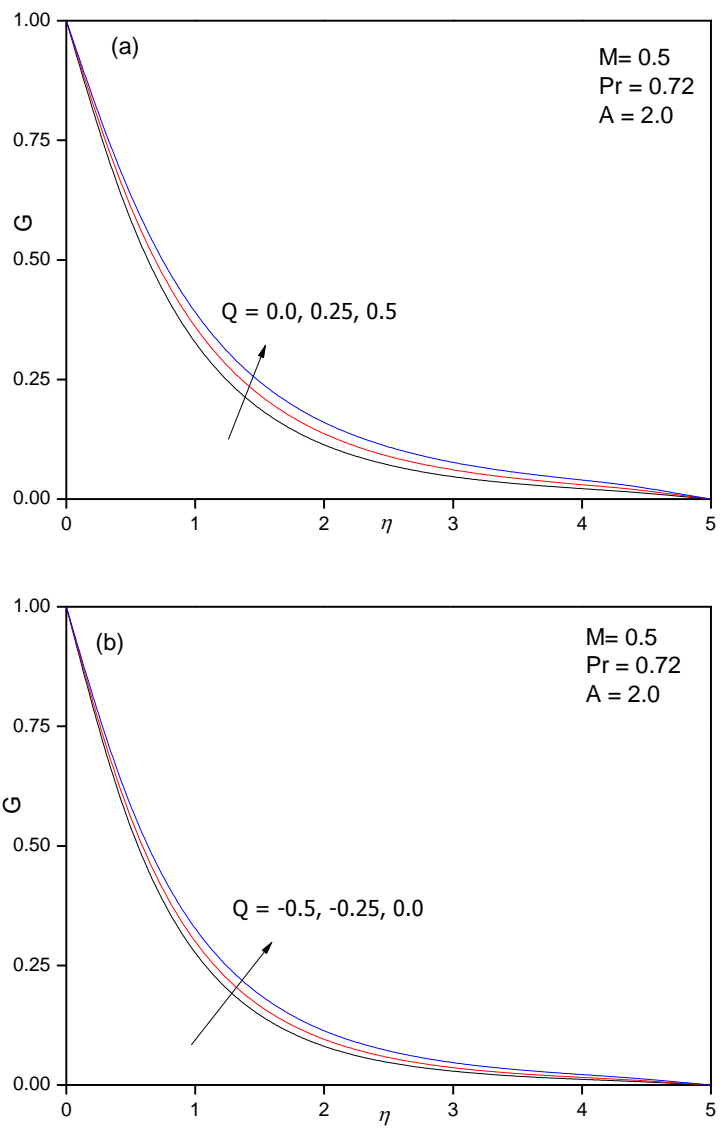

Figure 5(a) illustrates impact of heat generation $(Q>0)$ and (b) heat absorption parameter $(Q<0)$ on transfer of heat factor 
Figure 5 depicts the effect of the heat generation/absorption factor on temperature outlines when the Prandtl number $(\mathrm{Pr}=0.72)$ and magnetic parameter $(\mathrm{M}=0.5)$ are present.It is obviously believed that in the presence of heat generation and absorption together, the thermal boundary layer thickness is raised. In addition, it is evident from these considerations that the existing numerical findings support the conditions of the thermal boundary layer.

\section{CONCLUSIONS}

The foremost learning has noticed the consequence of heat generation/absorption. Hence, the skin friction aspect and the heat transfer factor rise with an upsurge of the magnetic field, and together the velocity and temperature profiles decline for the stable Prandtl number and in the absence of heat generation/absorption. It is evidently perceived that the thermal boundary layer thickness is declining in the existence of heat generation and increases for heat absorption. The temperature contours rise as a result of changes in heat generation and absorption. The future scope of the research work will include the radiation and pressure work parameters.

\section{CONFLICTOF INTEREST}

The writers authorize that this paper subjects have no conflict of interest.

\section{ACKNOWLEDGMENT}

One of the writers Ajaykumar M gratified to Principal and Management of Maharaja Institute of Technology Mysore571477 for their concerned provision.

\section{REFERENCES}

[1] Altan T, Oh S, Gegel H. 1979. Metal forming fundamentals and applications. Metals Park, $\mathrm{OH}$ : American Society of Metals.

[2] Fisher EG. 1976. Extrusion of plastics. New York: Wiley.

[3] Tidmore Z, Klein I. 1970. Engineering principles of plasticating extrusion, polymer science and engineering series. New York: Van Norstrand;
[4] Sakiadis BC. 1961 Boundary layer behaviour on continuous solid surface II, boundary layer behaviour on continuous flat surface. AIChE J ; 7:221-35

[5] L. J. Crane, 1970. Flow Past a Stretching Plate, Journal of Applied Mathematics and Physics (ZAMP), vol. 21, No. 4, pp. 645-647.

[6] S. Sharidan, T. Mahood and I. Pop, 2006. Similarity Solutions for The Unsteady Boundary Layer Flow and Heat Transfer Due to A Stretching Sheet, International Journal of Applied Mechanics and Engineering, vol. 11, No. 3, pp. 647-654.

[7] Ishak A, Naza R, Pop I. 2008. Hydromagnetic flow and heat transfer adjacent to a stretching vertical sheet. Heat Mass Transfer ; 44:921-7.

[8] Fadzilah MA, Nazar R, Arifin M, Pop I. 2011.MHD boundary-layer flow and heat transfer over a stretching sheet with induced magnetic field. J Heat Mass Transfer, 47,155-62.

[9] Samad M A, Mohebujjaman M. 2009. MHD heat and mass transfer free convection flow along a vertical stretching sheet in the presence of Magnetic field with heat generation. Res J Appl Sci, Eng Technol;1(3):98106

[10] H.T. Andersson, J.B. Aarseth, B.S. Dandapat, 2000. Heat transfer in a liquid film on an unsteady stretching surface, Int. J. Heat Transfer 43, 69-74.

[11] E.M.A. Elbashbeshy, M.A.A. Bazid, 2004. Heat transfer over an unsteady stretching surface, Heat Mass Transfer $41,1-4$

[12] K. Inouye and A. Tate, 1974. Finite difference version of quasilinearization applied to boundary later equations, AIAAJ.12, pp. 558-560.

[13] A. H. Srinivasa and A T Eswara, 2016. Effect of internal heat generation or absorption on MHD free convection from an isothermal truncated cone, Alexandria Engineering Journal, Volume 55, pp.1367-1373. 